\title{
Morfologia externa dos estágios imaturos de heliconíneos neotropicais: VI. Dione moneta moneta Hübner (Lepidoptera, Nymphalidae, Heliconiinae)
}

\author{
Lucas A. Kaminski ${ }^{1}$, Rafael Dell'Erba ${ }^{2}$ \& Gilson R. P. Moreira ${ }^{3}$
}

${ }^{1}$ PPG-Ecologia, Instituto de Biologia, Universidade Estadual de Campinas, Caixa Postal 6109, 13.083-970, Campinas-SP, Brasil. lucaskaminski@yahoo.com.br

${ }^{2}$ Departamento de Ciências Biológicas e da Saúde, IUniAraguaia, Universidade Federal do Mato Grosso, BR 100, km 3.5, 78.698-000, Pontal do Araguaia, Mato Grosso, Brasil.rafaeldellerba@yahoo.com.br

${ }^{3}$ Departamento de Zoologia, Instituto de Biociências, Universidade Federal do Rio Grande do Sul, Avenida Bento Gonçalves, 9500 , 91.501-970, Porto Alegre, Rio Grande do Sul, Brasil. gilson.moreira@ufrgs.br

\begin{abstract}
External morphology of the immature stages of Neotropical heliconines: VI. Dione moneta moneta Hübner (Lepidoptera, Nymphalidae, Heliconiini). The external features of the egg, larva and pupa of Dione moneta moneta Hübner, 1825 are described and illustrated, based upon light and scanning electron microscopy.
\end{abstract}

KEYWORDS. Egg; larva; Mexican Silverspot butterfly; Passiflora morifolia; pupa.

RESUMO. Morfologia externa dos estágios imaturos de heliconíneos neotropicais: VI. Dione moneta moneta Hübner (Lepidoptera, Nymphalidae, Heliconiini). As estruturas externas do ovo, larva e pupa de Dione moneta moneta Hübner, 1825 são descritas e ilustradas, baseadas em microscopia óptica e eletrônica de varredura.

PALAVRAS-CHAVE. Borboleta do maracujá; larva; ovo; Passiflora morifolia; pupa.

Dione moneta Hübner, 1825 é encontrada do sul dos Estados Unidos ao nordeste da Argentina e Uruguai (Biezanko 1949; Emsley 1963; Gilbert 1969; Biezanko et al. 1978; McCaffrey 1984; D’Abrera 1984). Três subespécies são reconhecidas por Lamas (2004): Dione moneta poeyii Butler, 1873, com distribuição na América Central; Dione moneta butleri Stichel, 1907, no norte da América do Sul e Andes; Dione moneta moneta Hübner, 1825, com ocorrência mais austral.

Os adultos têm hábito migratório, fator que pode explicar sua ampla distribuição geográfica e grandes flutuações anuais na abundância populacional (Gilbert 1969). São vistos geralmente no final do verão e início do outono, em ambientes abertos (Brown \& Mielke 1972; Garcias 1983; DeVries 1987; Brown 1992). As larvas se alimentam em Passifloraceae que possuem tricomas tectores em forma de gancho, tais como Passiflora adenopoda DC. e Passiflora warmingii Masters (= Passiflora morifolia Masters), dentre outras (Brown \& Mielke 1972; Benson et al. 1975; DeVries 1987). Na região Sudeste e Sul do Brasil, parece ser monófaga, alimentando-se somente de P. morifolia (Araújo \& Valente 1981; Garcias 1983; Brown 1992; Dell'Erba et al. 2005). Os tricomas, nesse caso, funcionam como uma defesa mecânica à herbivoria para a maioria das larvas de heliconíneos (Gilbert 1971). No entanto, os mecanismos morfológicos e/ou comportamentais que permitem às larvas de $D$. moneta evitarem o efeito letal correspondente ainda são pouco conhecidos. A oviposição é realizada diretamente sobre a passiflorácea, no limbo ou nas gavinhas, em clusters, de dois a 20 ovos (Brown 1944; Garcias 1983; Dell'Erba et al. 2005).
Apesar da ampla área de distribuição, informações sobre a biologia e morfologia dos estágios imaturos de $D$. moneta se resumem a descrições breves (Brown 1944; Brown 1981; DeVries 1987). Os estudos clássicos de Beebe et al. (1960) e Fleming (1960) sobre a morfologia dos estágios imaturos de heliconíneos de Trinidad não incluíram D. moneta. Penz (1999) propôs uma filogenia para os heliconíneos baseada na morfologia dos imaturos e adultos, mas não incluiu caracteres do primeiro instar para D. moneta. À exceção do estágio de ovo (descrito por Dell'Erba et al. 2005) e os estados de caracteres utilizados por Penz (1999), os imaturos ainda são desconhecidos do ponto de vista morfológico. Nesse sentido, dentro de uma série de estudos que vem sendo desenvolvidos sobre a morfologia dos estágios imaturos de heliconíneos neotropicais (Antunes et al. 2002; Kaminski et al. 2002; Tavares et al. 2002; Paim et al. 2004; Silva et al. 2006), o presente trabalho tem como objetivo identificar e descrever a morfologia tegumentar externa dos imaturos de $D$. moneta moneta, com base em microscopia óptica e eletrônica de varredura.

\section{MATERIALE MÉTODOS}

Os espécimes utilizados foram obtidos de ovos e larvas coletadas no campo sobre folhas ou gavinhas de $P$. morifolia, no Parque Estadual do Turvo, Derrubadas $\left(27^{\circ} 15^{\prime} \mathrm{S}, 53^{\circ} 55^{\prime} \mathrm{W}\right)$, e em plantas cultivadas no município de Porto Alegre ( $30^{\circ} 05^{\prime} \mathrm{S}$, $\left.51^{\circ} 10^{\prime} \mathrm{W}\right)$, Rio Grande do Sul, Brasil. Alguns ovos coletados no campo foram fixados para posterior análise e o restante permaneceu em placas de Petri com papel filtro úmido, até a eclosão. As larvas que eclodiram foram criadas em laboratório 
sobre ramos de P. morifolia. Os ramos foram mantidos em garrafas plásticas com suporte de arame, contendo água e cobertos por uma malha fina. O desenvolvimento larval foi acompanhado diariamente para reposição do alimento até a formação da pupa. As cápsulas cefálicas (exúvias) foram recolhidas e os imaturos separados por instar, fixados em Dietrich e preservados em etanol a 70\%. Os espécimes analisados encontram-se depositados sob os números 110, 142 e 163, na coleção do Laboratório de Morfologia e Comportamento de Insetos da UFRGS (LMCI-UFRGS), Porto Alegre, Brasil.

Os aspectos morfológicos genéricos foram estudados a partir de material fixado ou incluso em gelatina glicerinada. Para a descrição da quetotaxia primária, foram confeccionadas lâminas semipermanentes, a partir de exúvias e larvas dissecadas e clarificadas em solução de hidróxido de potássio $(\mathrm{KOH})$ a $10 \%$. Estas foram montadas em gelatina glicerinada e cobertas com lamínula. As ilustrações foram realizadas em um estereomicroscópio com o auxílio de uma grade micrométrica, com base na comparação de, no mínimo, cinco exemplares. Os padrões de coloração, em vivo, da larva de quinto instar e pupa, foram representados em aquarela. Aspectos ultraestruturais foram observados num Microscópio Eletrônico de Varredura. Para tal, as amostras foram desidratadas em um aparelho Bal-tec ${ }^{\circledR}$ - CPD030, montadas sobre suportes metálicos com fita dupla face, cobertas com ouro num metalizador Bal-tec ${ }^{\circledR}$ - SCD050, observadas e fotografadas num microscópio JEOL ${ }^{\circledR} 5800$.

A largura da cápsula cefálica (maior dimensão desta, em vista frontal) foi obtida com o auxílio de uma escala micrométrica acoplada à ocular de um estereomicroscópio, utilizando-se espécimes fixados em Dietrich. Os valores correspondentes foram ajustados pelo método dos mínimos quadrados à função $\mathrm{y}=\mathrm{ae}^{\mathrm{bx}}$ (Snedecor \& Cochran 1980).

Para a descrição do ovo, utilizou-se a nomenclatura proposta por Dell'Erba et al. (2005). A identificação das áreas do corpo da larva seguiu Peterson (1962). Para a quetotaxia da cápsula cefálica, utilizou-se o sistema proposto por Stehr (1987). As cerdas do labro seguiram a terminologia de Peterson (1962). Para a quetotaxia do tórax, abdômen e padrão dos ganchos do larvópodo foi adotada a nomenclatura de Stehr (1987), com exceção das cerdas da seção cilíndrica do larvópodo do décimo segmento, que seguiram Kitching (1984). Para a descrição dos escolos, foi adotado Beebe et al. (1960). A terminologia utilizada para a pupa foi a de Mosher (1916) e Beebe et al. (1960).

\section{RESULTADOSEDISCUSSÃO}

Ovo. Apresenta coloração amarela e próximo à eclosão da larva surgem manchas marrons aleatoriamente distribuídas, vistas por transparência do cório. Tal padrão é semelhante ao observado para outros gêneros de Heliconiini, como Agraulis Boisduval \& Le Conte, 1833, Dryadula Michener, 1942 e Dryas Hübner, 1807 (Paim et al. 2004; Dell'Erba et al. 2005; Silva et al. 2006). Conforme Dell'Erba et al. (2005), o ovo possui base plana e ápice afilado (Fig. 1). Para os 10 espécimes analisados, o diâmetro (média \pm erro padrão) foi de $0,932 \pm 0,009 \mathrm{~mm}$ e altura de 1,129 $\pm 0,008 \mathrm{~mm}$. Os valores são similares aos encontrados por Brown (1944) e Brown Jr. (1981).
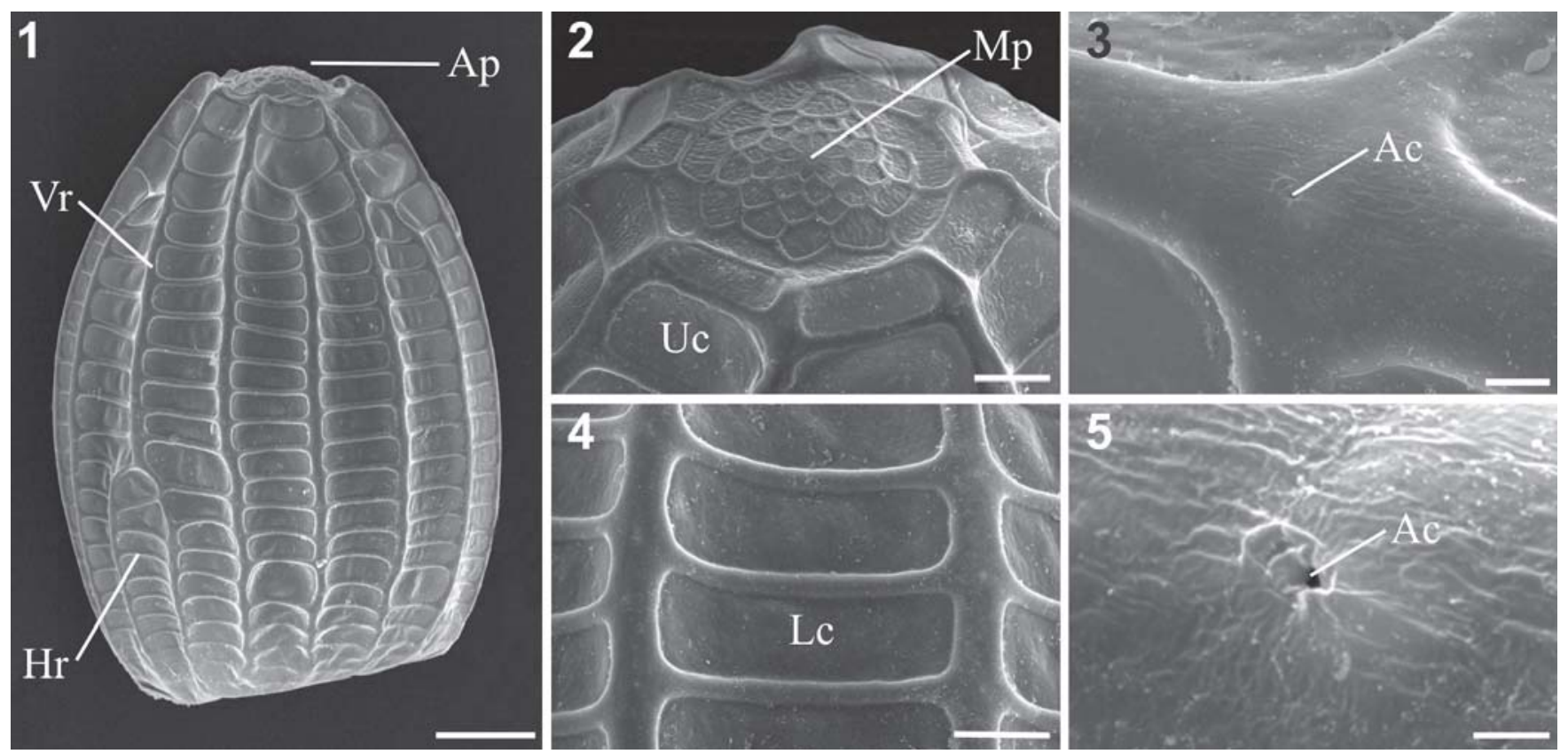

Figs. 1-5. Ovo de Dione moneta moneta Hübner, 1825 em microscopia eletrônica de varredura. 1, vista lateral; 2, região micropilar; 3, detalhe da intersecção das carenas; 4, células inferiores; 5, aerópila. Ac, aerópila. Ap, pólo anterior; Hr, carena horizontal; Lc, célula inferior; Mp, micrópilas; Uc, célula superior; Vr, carena vertical. Barras $=200,50,50,20$ e $10 \mu \mathrm{m}$, respectivamente. 

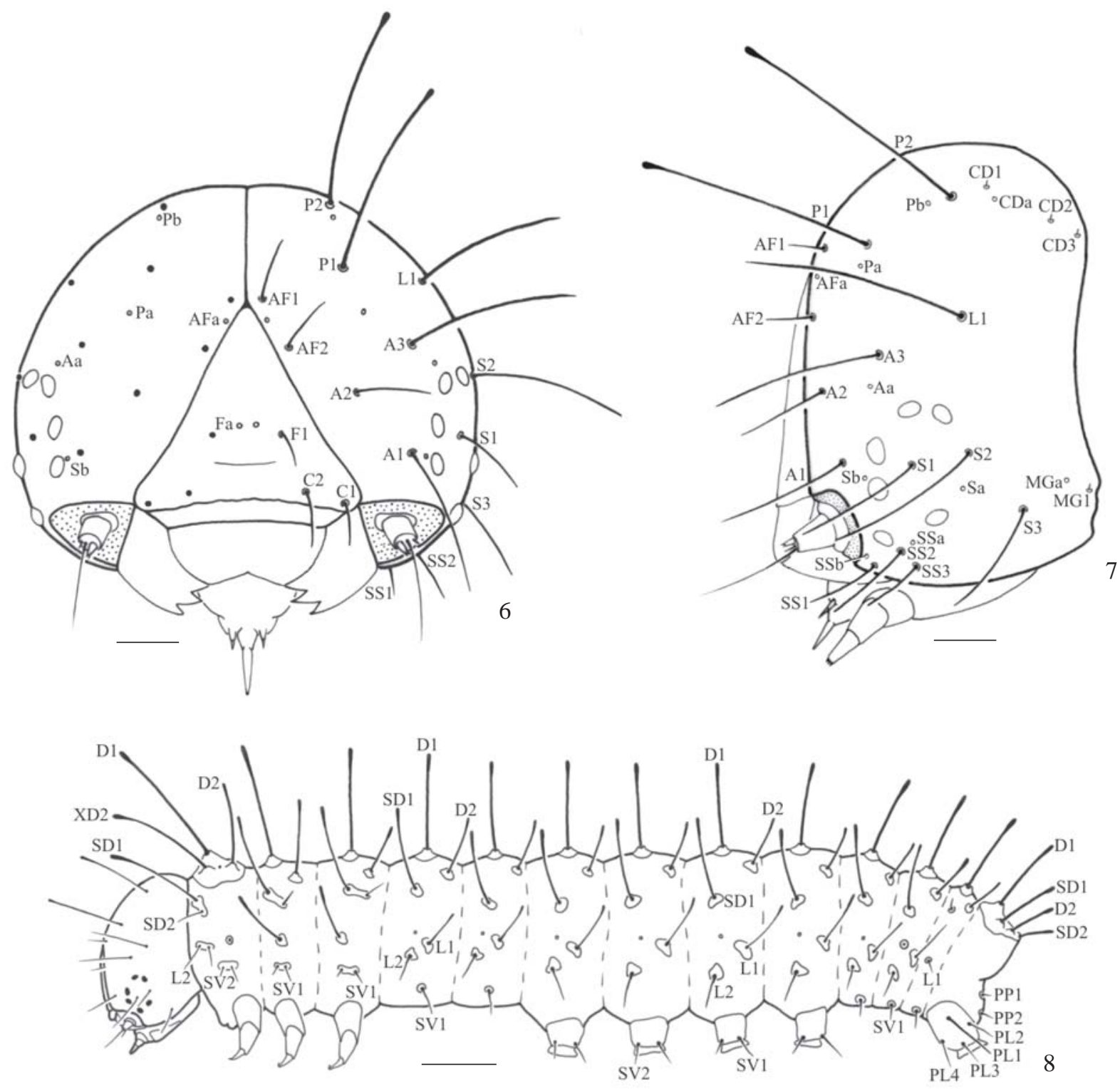

Figs. 6-8. Larva de primeiro instar de Dione moneta moneta Hübner, 1825. 6, cápsula cefálica em vista frontal (cerdas omitidas do lado direito); 7, cápsula cefálica em vista lateral; 8, larva em vista lateral. A, grupo anterior; AF, grupo adfrontal; C, grupo clipeal; CD, grupo céfalo-dorsal; D, grupo dorsal; F, grupo frontal; L, grupo lateral; MG, grupo microgenal; P, grupo póstero-dorsal; PL, grupo da seção cilíndrica do larvópodo do $10^{\circ}$ segmento abdominal; PP, grupo paraproctal; S, grupo estematal; SD, grupo subdorsal; SP, grupo subparaproctal; SS, grupo subestematal; SV, grupo subventral; XD, grupo protorácico. Barras $=100,100$ e $500 \mu \mathrm{m}$, respectivamente.

O cório é ornamentado por carenas de superfície lisa (Figs. 3-4), com as verticais ( $\mathrm{Vr}$ ) variando em número de 15 a 16 e, as horizontais $(\mathrm{Hr})$, de 16 a $18(\mathrm{n}=10)$. Os valores são similares aos obtidos por Brown (1981), sendo o baixo número de carenas horizontais (7) registrado por Brown (1981) um erro de grafia (K. S. Brown Jr., UNICAMP, com. pess.). Semelhante ao observado para Agraulis vanillae maculosa (Stichel, [1908]) e Dione juno juno (Cramer, 1779) (Tavares et al. 2002; Silva et al. 2006), as carenas verticais de D. moneta moneta tem o dobro da largura das horizontais e algumas apresentam-se interrompidas, à distância de duas ou três células da região micropilar.
Tabela I. Média aritmética e erro padrão, intervalo de variação e razão de crescimento da largura da cápsula cefálica dentre os instares larvais de Dione moneta moneta, criados sobre Passiflora morifolia, $\mathrm{n}=20$ / instar.

\begin{tabular}{cccc}
\hline \multirow{2}{*}{ Instar } & \multicolumn{3}{c}{ Largura da cápsula cefálica $(\mathrm{mm})$} \\
& $\begin{array}{c}\text { Média } \pm \text { Erro } \\
\text { Padrão }\end{array}$ & $\begin{array}{c}\text { Intervalo de } \\
\text { Variação }\end{array}$ & $\begin{array}{c}\text { Razão de } \\
\text { Crescimento }\end{array}$ \\
\hline I & $0,522 \pm 0,005$ & $0,486-0,558$ & --- \\
II & $0,829 \pm 0,007$ & $0,774-0,882$ & 1,59 \\
III & $1,360 \pm 0,011$ & $1,295-1,443$ & 1,43 \\
IV & $2,059 \pm 0,016$ & $1,976-2,184$ & 1,51 \\
V & $3,042 \pm 0,036$ & $2,808-3,224$ & 1,48 \\
\hline
\end{tabular}



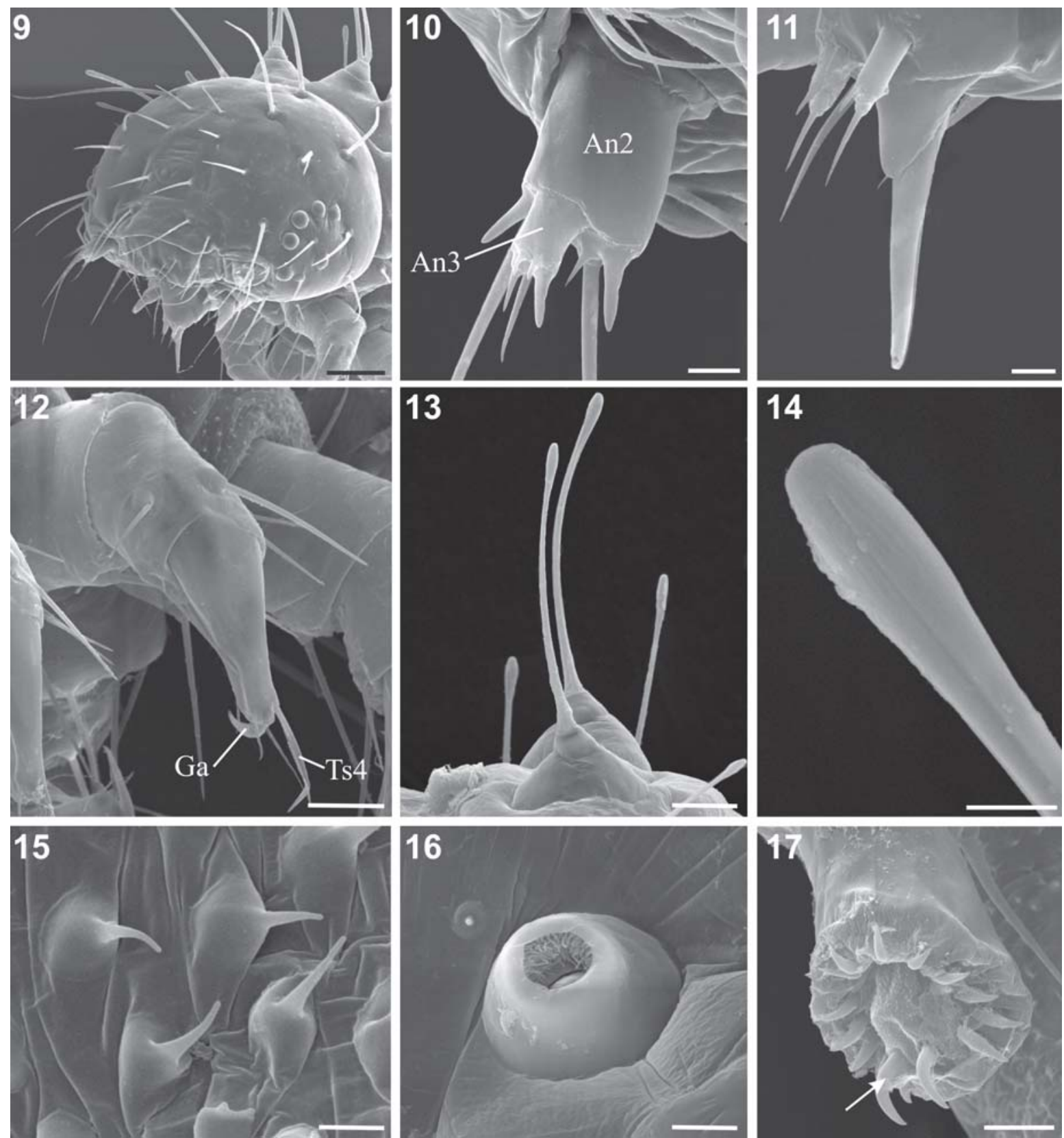

Figs. 9-17. Larva de primeiro instar de Dione moneta moneta Hübner, 1825 em microscopia eletrônica de varredura. 9, cápsula cefálica em vista látero-frontal; 10, antena; 11, espinarete; 12, perna mesotorácica; 13, cerdas do tipo calaza; 14, porção apical de uma cerda; 15, microtríquias; 16, espiráculo abdominal; 17, planta do larvópodo com ganchos expostos (seta). An, artículo antenal; Ga, garra; Ts, cerda tibial. Barras = 100, 10, $10,50,50,10,5,10$ e $30 \mu \mathrm{m}$, respectivamente.

As células delimitadas pela intersecção das carenas possuem os ângulos internos arredondados e tendem à superfície lisa (Figs. 3-4). O padrão liso destas parece ser uma característica dos Heliconiini, com rugosidades presentes apenas no gênero Heliconius Kluk, 1802 (Dell'Erba et al. 2005). As células superiores $(\mathrm{Uc})$ variam de retangulares a pentagonais, e as inferiores (Lc) são retangulares (Fig. 4). As aerópilas (Ac) presentes nas intersecções das carenas são circulares, sem elevações no peritrema (Fig. 5). Células da região micropilar de formato poligonal no ânulo e, pentagonal ou hexagonal, na roseta; todas com suaves rugosidades.
Larvas. No primeiro instar, a larva apresenta coloração marrom clara. Após a alimentação, o conteúdo intestinal é visível por transparência, como uma faixa esverdeada. Cápsula cefálica, calazas, pináculos e cerdas maiores de coloração castanha escura e, cerdas menores, translúcidas. Morfologia geral da cápsula cefálica e peças bucais (Figs. 6-7, 9-11) seguindo o padrão geral para Lepidoptera (Stehr 1987). Fronte e clípeo fusionados, com sutura frontoclipeal pouco evidente. Anteclípeo presente, ligando o labro ao frontoclípeo. Mandíbulas parcialmente cobertas em vista frontal. Antena (Fig. 10), inserida na antacória, formada por três artículos: o 


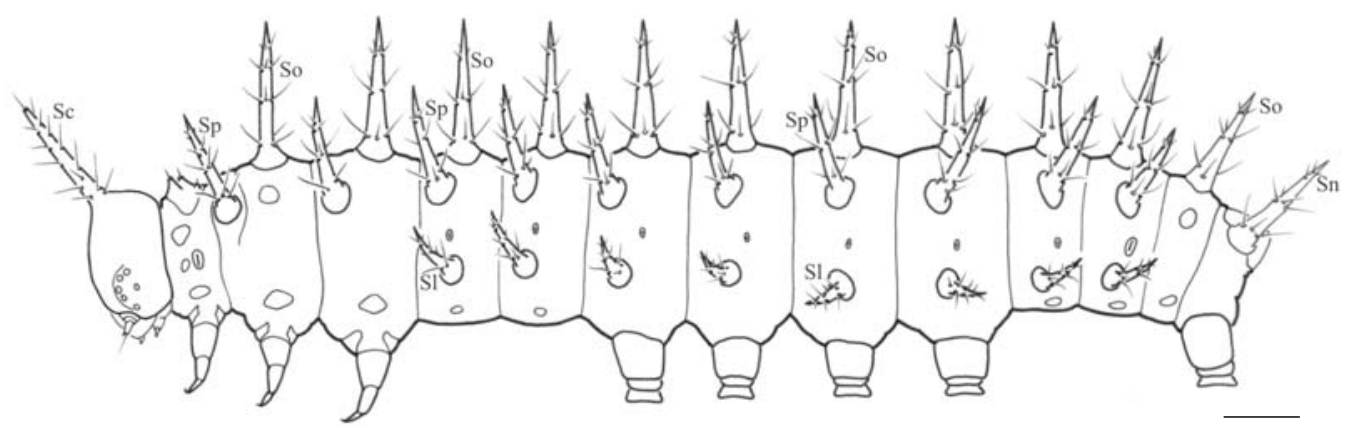

Fig. 18. Larva de quinto instar de Dione moneta moneta Hübner, 1825 em vista lateral. Sc, escolo cefálico; S1, escolo subespiracular; Sn, escolo anal; So, escolo dorsal; Sp, escolo supraespiracular. Barra $=1,2 \mathrm{~mm}$.
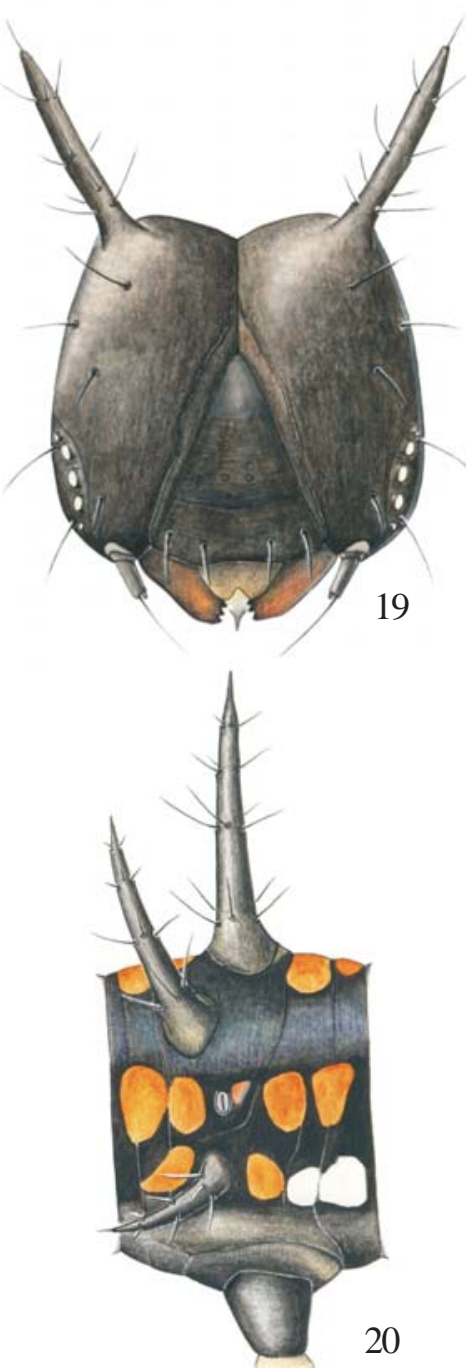
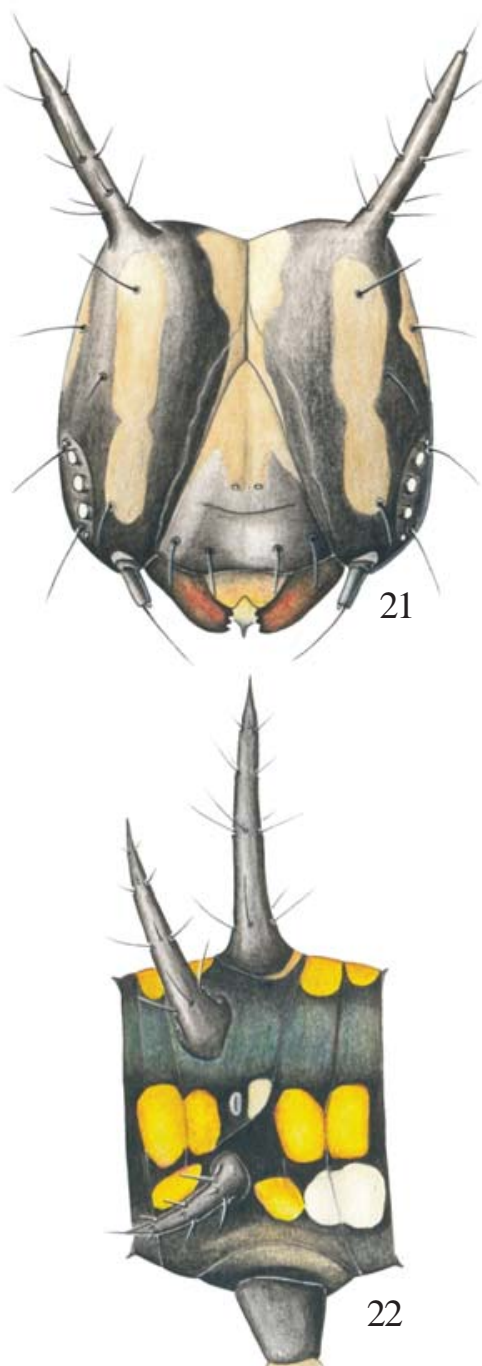
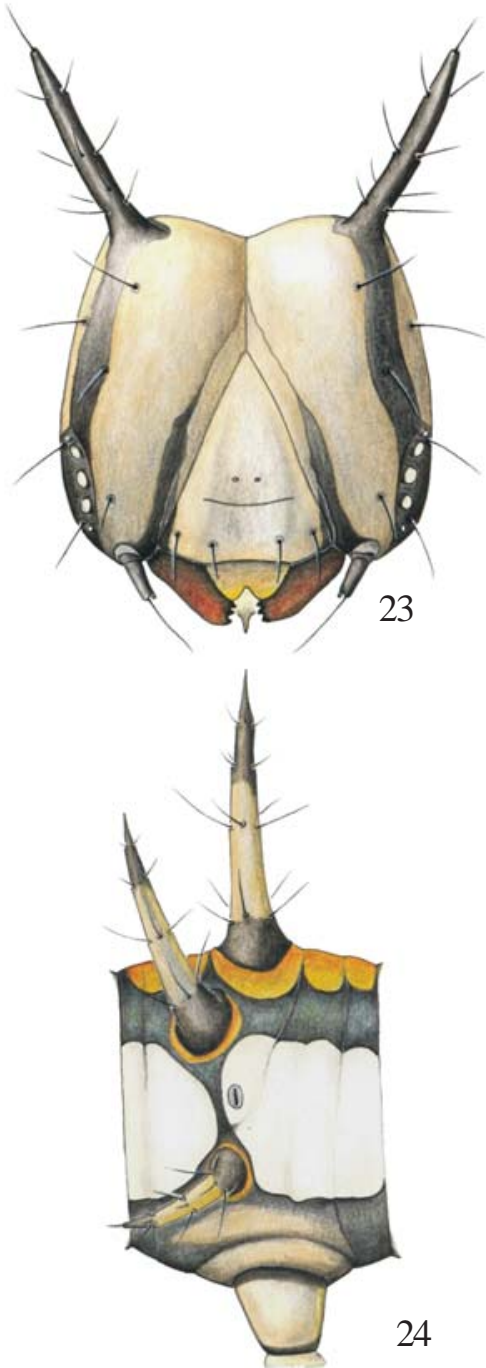

Figs. 19-24. Variação no padrão de coloração das larvas de quinto instar de Dione moneta moneta Hübner, 1825, demonstrado esquematicamente para a cápsula cefálica e quarto segmento abdominal. 19-20, padrão escuro; 21-22, padrão intermediário; 23-24, padrão claro.

primeiro curto e alargado; o segundo alongado, com sensilas; e, o terceiro, curto com sensilas.

De maneira geral, a quetotaxia é semelhante à descrita para outros heliconíneos (ver Fleming 1960; Antunes et al. 2002; Kaminski et al. 2002; Tavares et al. 2002; Paim et al. 2004; Silva et al. 2006). Cerdas lisas, do tipo calaza com ápice dilatado
(Figs. 8, 13-14). Tais dilatações nas cerdas primárias já haviam sido detectadas em D. moneta por Brown (1944), tendo sido descrito para o primeiro instar de diversas espécies de Heliconiini (Kaminski et al. 2002; Paim et al. 2004; Silva et al. 2006) e Satyrinae (Murray 2001; Freitas 2003).

Na cápsula cefálica (Figs. 6-7, 9), estão presentes 21 pares 

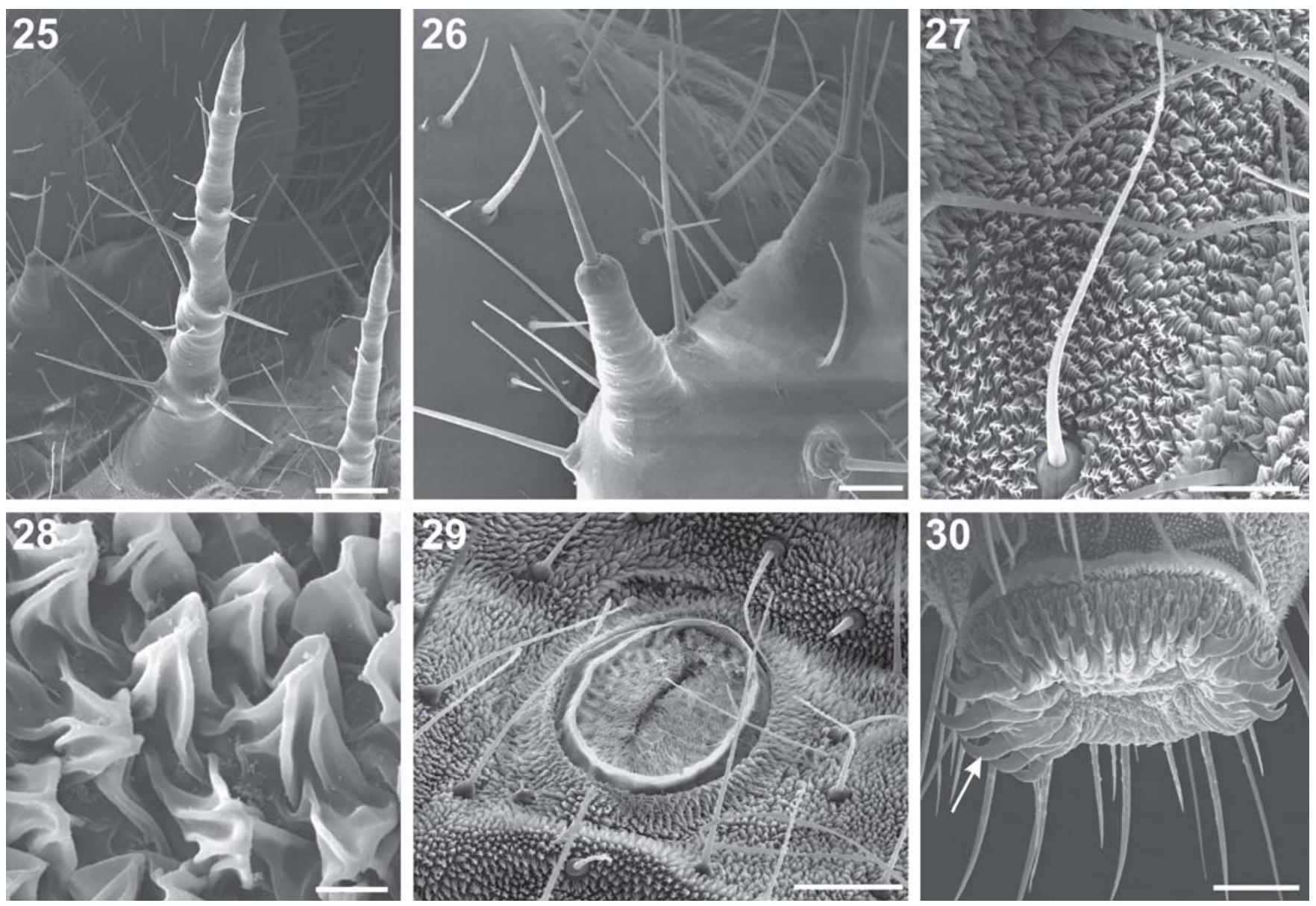

Figs. 25-30. Larva de quinto instar de Dione moneta moneta Hübner, 1825 em microscopia eletrônica de varredura. 25, escolo dorsal; 26, placa protorácica; 27, cerda secundária; 28, microtríquias; 29, espiráculo abdominal; 30, planta do larvópodo, com ganchos expostos (seta). Barras = $250,100,50,5,100$ e $100 \mu \mathrm{m}$, respectivamente.

de cerdas (incluindo quatro pares de microcerdas) e 11 pares de poros. Estes foram agrupados em 10 grupos: Grupo adfrontal (AF), composto pelas cerdas AF1 e AF2, próximas ao ângulo superior do frontoclípeo; poro $\mathrm{AFa}$, posicionado medianamente entre as duas cerdas adfrontais. Grupo anterior (A), com as cerdas A1, A2 e A3 formando um triângulo imaginário, em vista frontal; Poro Aa associado aos estematas 2 e 3, conforme observado para outros Heliconiinae, Nymphalinae e Satyrinae (Nakanishi 1988; Murray 2001; Paluch et al. 2001; Antunes et al. 2002; Paim et al. 2004), e diferente do observado para Danainae e Ithomiinae, que apresentam Aa posicionado entre a cerda A2 e o frontoclípeo (Kitching 1984; Motta 2003). Grupo clipeal (C) constituído pelas cerdas C1 e C2. Grupo céfalo-dorsal (CD sensu Duarte et al. $2005,=$ V sensu Hinton 1946, = MD sensu Stehr 1987) com as microcerdas $\mathrm{CD} 1, \mathrm{CD} 2$ e $\mathrm{CD} 3$ posteriores a $\mathrm{P} 2$; poro $\mathrm{CDa}$ posicionado entre $\mathrm{CD} 1$ e CD2, sendo a posição relativa deste poro semelhante ao descrito para outros Heliconiini e Acraeini (Paluch et al. 2001; Kaminski et al. 2002; Paim et al. 2004; Silva et al. 2006). Grupo frontal (F) composto pela cerda $\mathrm{F} 1$; poro $\mathrm{Fa}$ localizado entre as cerdas frontais. Grupo lateral (L) com a cerda L1 posicionada ântero-dorsal em relação ao poro La.
Grupo microgenal (MG) constituído pela microcerda MG1 e pelo poro MGa. Grupo póstero-dorsal (P), cerda P1 ventral em relação à $\mathrm{P} 2$ com tamanhos aproximados; poro Pa localizado ventralmente em relação à $\mathrm{Pb}$. Grupo estematal $(\mathrm{S})$, constituído pelas cerdas $\mathrm{S} 1, \mathrm{~S} 2$ e $\mathrm{S} 3$; poro $\mathrm{Sa}$ ventral à cerda $\mathrm{S} 2 \mathrm{e}$, poro $\mathrm{Sb}$, associado ao estemata 4. Grupo subestematal (SS), com cerdas SS1, SS2 e SS3; poro SSa dorsal à SS2 e SSb próximo à antacória. O labro apresenta seis pares de cerdas, M1, M2 e M3 próximo à margem do labro, e cerdas LA1, LA2, LA3 na margem do labro. Outras cerdas menores associadas às peças bucais, como maxila e mandíbula não foram nomeadas (ver Stehr 1987).

No corpo (Fig. 8), cerdas do tipo calaza distribuídas em sete grupos, de acordo com a posição (dorsal D, lateral L, placa protorácica XD, subdorsal SD, subventral SV, paraproctal $\mathrm{PP}$ e ventral V). Poros e microcerdas estão presentes no corpo, os quais foram omitidos na descrição da quetotaxia.

Placa protorácica com cerdas D1, D2, XD2 e poro XDc. Cerda SD1 maior que SD2; ambas no mesmo pináculo. Cerdas L1 e L2 de tamanho aproximado, e anteriores ao espiráculo protorácico, sendo L1 posterior a L2. Cerdas do grupo subventral inseridas em um pináculo posicionado ventralmente ao espiráculo, sendo SV1 posterior a SV2. Meso- e metatórax 


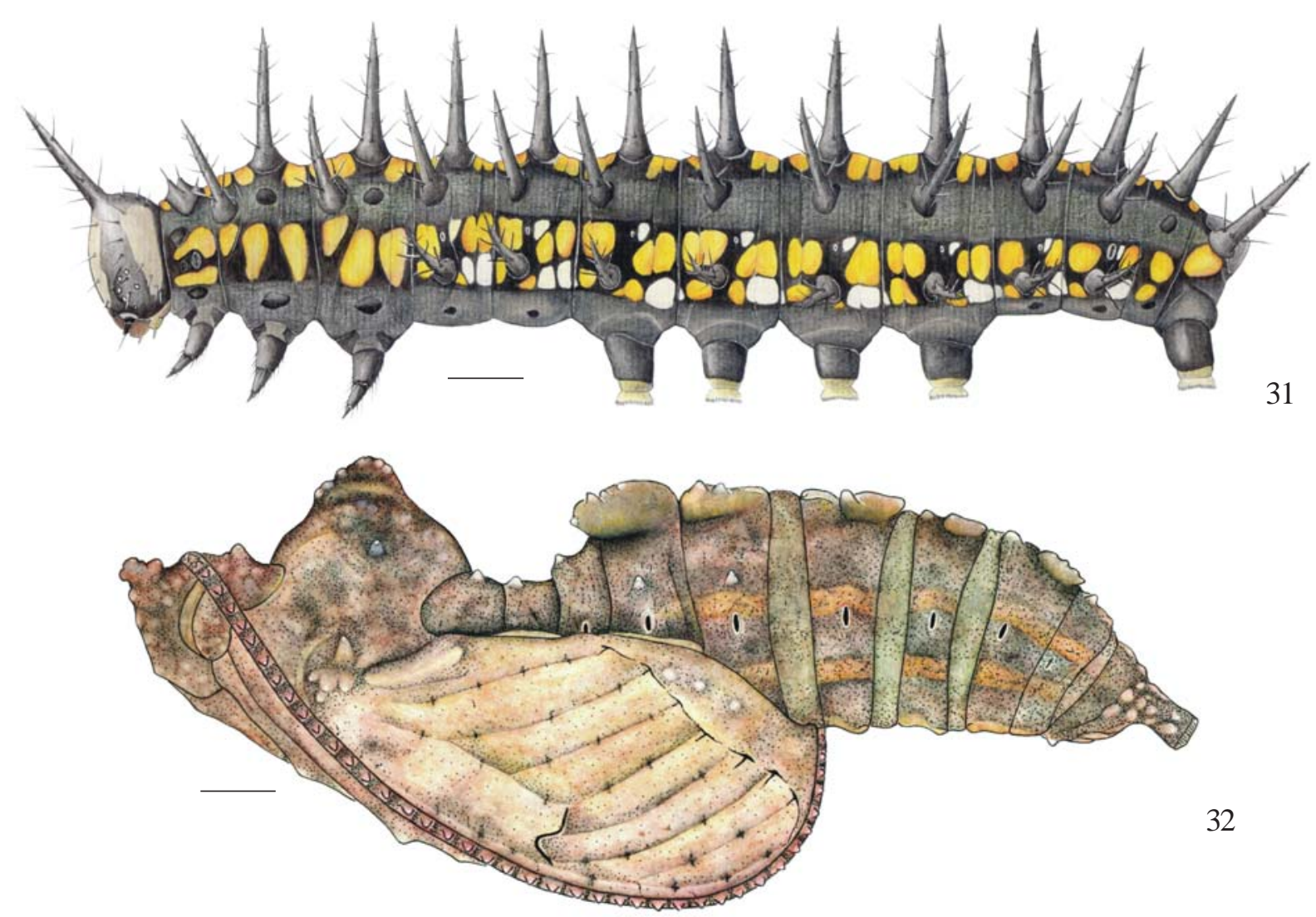

Figs. 31-32. Padrão de coloração de Dione moneta moneta Hübner, 1825. 31, larva de quinto instar; 32, pupa. Barras = 1,2 mm.

com cerdas dorsais D1 e D2 situadas em pináculos separados; D1 maior e mais dorsal que D2. Grupo subdorsal representado apenas por SD1 e, o lateral, por L1. Grupo subventral formado por SV1 e SV2, posicionadas como no protórax. Pernas com cerdas tibiais e tarsais representadas por Ts1, Ts2, Ts3 e Ts4 (sensu Miller 1991), sendo Ts4, longa e curvada, semelhante à garra (Ga, Fig. 12).

No abdômen, o grupo dorsal é representado pelas cerdas D1 e D2 em todos os segmentos. O subdorsal, do primeiro ao décimo segmento, pela cerda SD1, e SD2 apenas no décimo. As laterais (L1 e L2), em pináculos individuais do primeiro ao oitavo segmento e, no nono segmento, apenas L1, pequena e fina. Grupo subventral, com a cerda SV1 do primeiro ao nono segmento abdominal e, SV2 do segundo ao sexto, e nono segmento. As cerdas subventrais do terceiro ao sexto segmento estão inseridas nas seções cilíndricas dos larvópodos. Grupo ventral formado por cerdas V1 curtas e finas. No paraprocto, cerda paraproctal PP1 e subparaproctal SP1, em pináculos separados. Na seção cilíndrica do larvópodo do décimo segmento abdominal, situam-se as cerdas PL1, PL2, PL3 e PL4, com PL5 posicionada ventralmente. A quetotaxia do décimo segmento abdominal é semelhante ao descrito para Danainae (Kitching 1984) e para os outros Heliconiini (Antunes et al. 2002; Kaminski et al. 2002; Tavares et al. 2002; Paim et al. 2004; Silva et al. 2006).

Tegumento com microtríquias (Fig. 15), em maior quantidade na região ventral. Espiráculos (Fig. 16) arredondados, com peritrema elevado, localizados no protórax e no primeiro ao oitavo segmento abdominal. Larvópodos (Fig. 17) localizados do terceiro ao sexto, e no décimo segmentos abdominais, com ganchos uniordinais e unisseriais.

A partir do segundo instar, o padrão de coloração das larvas é bastante variável. No quinto, é possível identificar três padrões de coloração: um escuro (Figs. 19-20), com cápsula cefálica, escolos e seções cilíndricas dos larvópodos preto, coloração de fundo cinza-escuro com manchas dorsais e laterais brancas e alaranjadas; um intermediário (Figs. 21-22, 31 ), com cápsula cefálica preta contendo faixas verticais bege, escolos e seções cilíndricas dos larvópodos preto, coloração de fundo cinza-escuro com manchas dorsais e laterais brancas e amareladas; e um claro (Figs. 23-24), com cápsula cefálica bege com faixas preta, escolos e seções cilíndricas dos larvópodos bege e preto, coloração de fundo cinza com manchas dorsais amareladas e laterais formando uma faixa longitudinal creme. Em Heliconiini, a variação interespecífica no padrão de coloração das larvas tem sido observada também em A. vanillae maculosa e Dione glycera (Felder \& Felder, 1861) (Toledo 1991; Silva et al. 2006; L. A. Kaminski dados inéditos), mas as bases genética e/ou fisiológica, bem como as implicações evolutivas destas variações ainda são desconhecidas.

Quanto à quetotaxia, a principal mudança observada após 


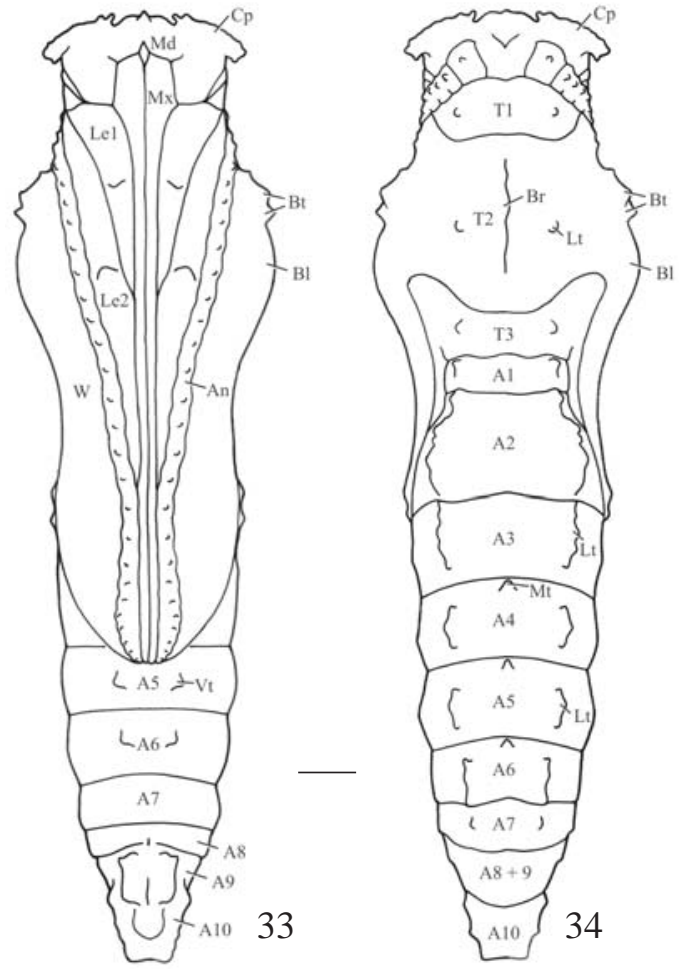

Figs. 33-34. Pupa de Dione moneta moneta Hübner, 1825. 33, vista ventral; 34, vista dorsal. A, segmento abdominal; An, antena; B1, crista longitudinal; Br, crista médio-dorsal; Bt, tubérculo basilar; $\mathrm{Cp}$, projeção cefálica; Le, perna; Lt, tubérculo lateral; Md, mandíbula; Mt, tubérculo médio-dorsal; Mx, maxila; T, segmento torácico; Vt, tubérculo ventral; $\mathrm{W}$, asa. Barra $=1,0 \mathrm{~mm}$ o primeiro instar é a substituição das cerdas primárias por cerdas secundárias, escolos e verrucas (Figs. 18, 25-26). O posicionamento dos escolos segue o descrito para outros Heliconiini (Beebe 1960), correspondente a 31 pares (Fig. 18): um cefálico $(\mathrm{Sc}), 11$ dorsais (So), 10 supraespiraculares (Sp), oito laterais ( $\mathrm{Sl}$ ) e um anal (Sn). Escolos cefálicos longos e curvados. Escolos supraespiraculares, do meso- e metatórax deslocados anteriormente, conforme descrito para outros Heliconiini (Müller 1886; Harvey 1991). Placa protorácica (Fig. 26) com três pares de cerdas inseridas em projeções curtas, que apesar de serem homólogas aos escolos protorácicos de D. juno juno (Penz 1999), não podem ser consideradas escolos verdadeiros (sensu Stehr 1987). Pares de verrucas em posição semelhante aos pináculos primários, sendo três no protórax, dois no meso- e metatórax, um no primeiro, segundo, sétimo e oitavo segmentos abdominais, e dois no nono.

Escolos (Fig. 25) com cerdas de dois tipos: 1) longas e afiladas, e 2) curtas, com porção terminal dilatada a semelhança do primeiro instar. Porção distal do escolo afilada, constituída por uma cerda fracamente delimitada, como observada para outros Heliconiini (Kaminski et al. 2002; Paim et al. 2004; Silva et al. 2006). Cerdas secundárias (Fig. 27), com aproximadamente $350 \mu \mathrm{m}$ de comprimento, cerca de cinco vezes mais longas que aquelas de A. vanillae maculosa, D. juno juno, Dryas iulia alcionea (Cramer, 1779) e Heliconius erato phyllis (Fabricius, 1775). Cerdas marcadamente longas em $D$. moneta e $D$. glycera já haviam sido detectadas por Penz (1999).
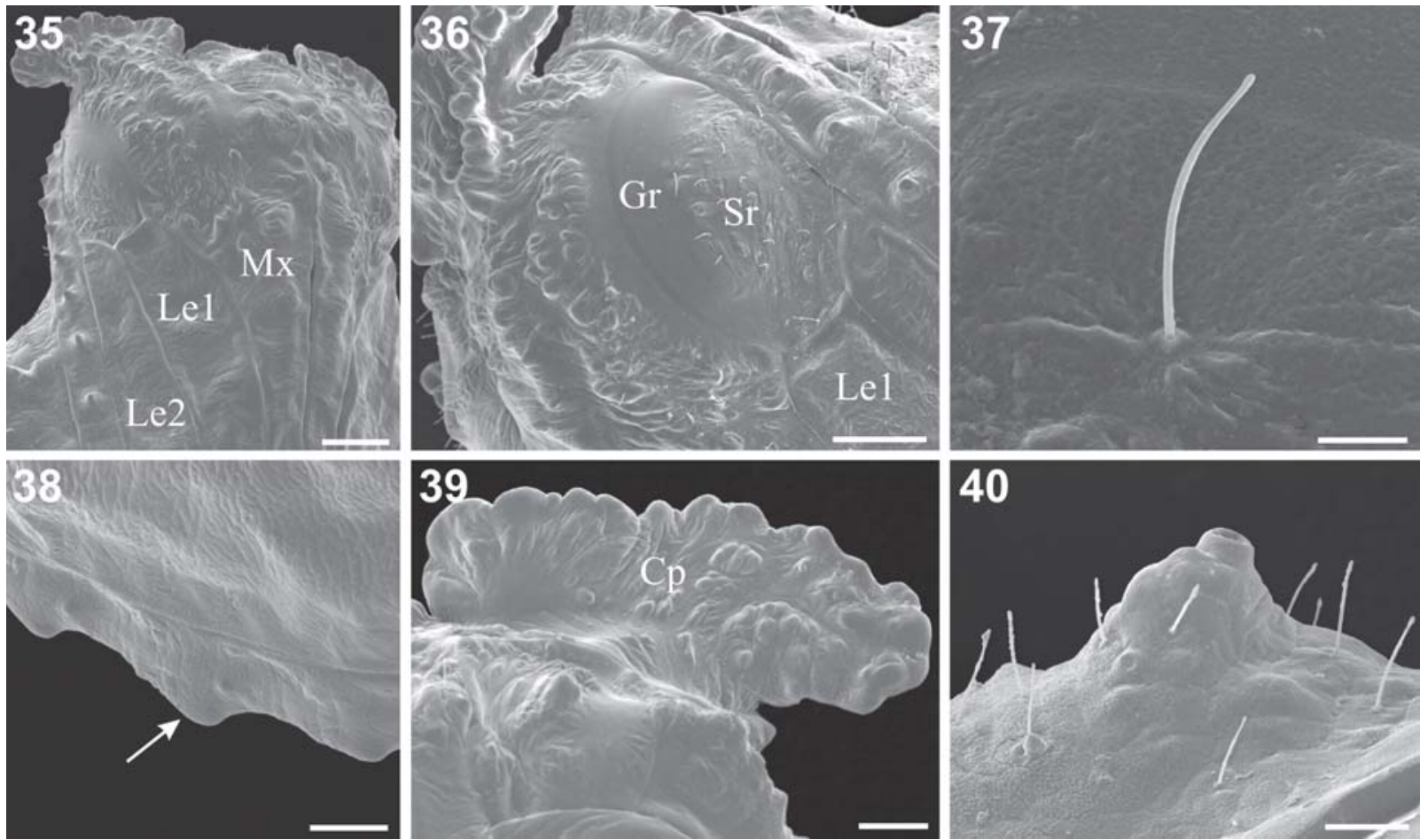

Figs. 35-40. Pupa de Dione moneta moneta Hübner, 1825 em microscopia eletrônica de varredura. 35, cabeça em vista látero-ventral; 36, cabeça em vista lateral; 37, cerda do protórax; 38, porção mediana da antena com tubérculos (seta); 39, projeção cefálica em vista dorsal; 40, tubérculo lateral do protórax. Cp, projeção cefálica; Le, perna; Gr, faixa de aspecto reluzente do olho; Mx, porção proximal da maxila; Sr, porção esculturada do olho. Barras $=500,500,50,200,250$ e $100 \mu \mathrm{m}$, respectivamente. 

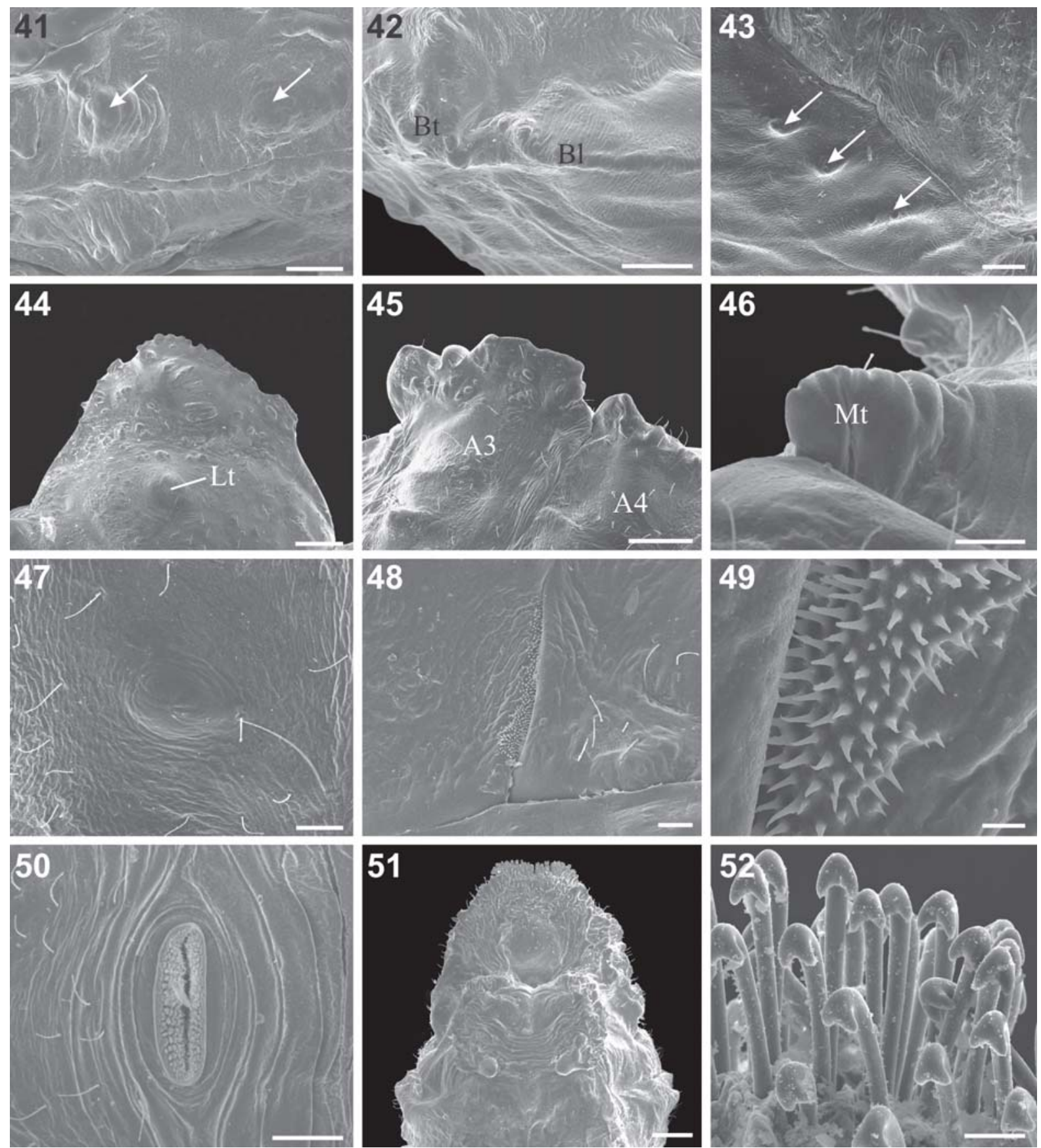

Figs. 41-52. Pupa de Dione moneta Hübner, 1825 em microscopia eletrônica de varredura. 41, porção proximal das maxilas evidenciando tubérculos (setas); 42, vista lateral da porção proximal da asa; 43, vista lateral da porção distal da asa com tubérculos (setas); 44, mesotórax em vista lateral; 45, tubérculos laterais do $3^{\circ}$ e $4^{\circ}$ segmentos abdominais; 46, tubérculo médio-dorsal; 47, tubérculo supraespiracular; 48, espiráculo mesotorácico; 49, detalhe da abertura do espiráculo mesotorácico; 50, espiráculo do $5^{\circ}$ segmento abdominal; 51 , crêmaster em vista ventral; 52 , ganchos do crêmaster. A, segmento abdominal; Bl, crista longitudinal; Bt, tubérculo basilar; Lt, tubérculo lateral; Mt, tubérculo médio-dorsal. Barras $=200,500,500,500,500,100,200,100,20,100,500$ e $50 \mu \mathrm{m}$, respectivamente.

Tegumento coberto por microtríquias (Figs. 27-29); cônicas e estriadas na região dorso-lateral, afiladas na ventral, e espatuladas na planta dos larvópodos. Espiráculos (Fig. 29) elípticos, com peritrema levemente elevado e aparato filtrador evidente, sendo o protorácico e o oitavo abdominal maiores que os demais. Ganchos dos larvópodos unisseriais (Fig. 30), com diversos tamanhos (multiordinal).
Identificação dos instares. A variabilidade no padrão de coloração das larvas de $D$. moneta moneta dentre os instares não permite a identificação segura dos mesmos com base em características de coloração. Como procedimento alternativo para a identificação dos mesmos foi tomada a medida da largura da cápsula cefálica de larvas criadas em laboratório. A partir destes dados foram obtidas medidas de tendência central e de 
dispersão dentre os instares que se ajustaram à seguinte equação de crescimento: $\ln y=447 x-1,079 ; n=100 ; r=0,996$; $\mathrm{p}<0,0001$. As medidas de crescimento da cápsula cefálica seguiram a regra de Brooks-Dyar, com razão média de crescimento dentre os instares igual a 1,50. Este valor é semelhante ao encontrado para outros heliconíneos (Antunes et al. 2002; Kaminski et al. 2002; Tavares et al. 2002; Paim et al. 2004; Silva et al. 2006). A ausência de sobreposição de valores dentre os instares permite a identificação acurada dos mesmos (Tab. I).

Pupa. Apresenta coloração variável, sendo constituída por uma mistura de tonalidades de marrom e cinza (Fig. 32). No primeiro e segundo segmentos abdominais, estão presentes pares de manchas douradas associadas aos tubérculos laterais. A presença destas manchas é uma característica diagnóstica para diferenciá-la da pupa de $D$. juno juno (ver Beebe et al. 1960; Toledo 1991; Tavares et al. 2002). Variação na intensidade da coloração das pupas é visível tanto entre indivíduos quanto ao longo da ontogênese.

Quanto à morfologia genérica, a pupa segue o padrão geral proposto por Mosher (1916) para Nymphalidae, com sutura epicranial ausente, pernas protorácicas e mesotorácicas estendidas ântero-ventralmente, até a margem posterior da região ocular (Figs. 33-36). Peças bucais fundidas em vista ventral (Fig. 33). Mandíbulas posicionadas lateralmente ao labro (Figs. 33, 35). Par de maxilas longas e posteriores ao labro (Figs. 33, 35). Região ocular dividida em duas partes, uma de aspecto lisa e outra áspera com cerdas (Fig. 36). Antena origina-se dorsalmente e se estende ventralmente até a porção distal das asas.

Pupa pertencente ao "Grupo A" de Beebe (1960), caracterizado pela ausência de espinhos e flanges, e com projeções cefálicas curtas. Em geral, o tegumento é levemente corrugado com diversos tubérculos pequenos, como os presentes na porção proximal das maxilas (Fig. 41), pernas e artículos antenais (Figs. 33, 38). Projeção cefálica curta, com formato de concha, achatada dorso-ventralmente e superfície corrugada (Figs. 33-34, 39). Asas com pequenos tubérculos típicos de Heliconiini (Beebe et al. 1960). Na porção proximal da asa, tubérculos basilares seguidos de uma crista longitudinal (Fig. 42). Na porção distal, três pares de tubérculos pósmedianos e três sub-marginais (Fig. 43).

Conforme descrito por Mosher (1916) para outros Nymphalidae, os tubérculos maiores estão distribuídos em quatro grupos: tubérculos laterais, médio-dorsais, supraespiraculares e ventrais. Associadas aos tubérculos estão presentes cerdas (Figs. 37 e 40), relativamente maiores em relação às cerdas das pupas de outros Heliconiini. Dentre os tubérculos destacam-se os laterais situados láteroventralmente, do protórax ao sétimo segmento abdominal (Figs. $34,40,45)$. Entre o terceiro e quarto segmentos abdominais, os tubérculos laterais encontram-se fundidos, formando uma crista em vista lateral (Fig. 45).

Crista médio-dorsal no mesotórax bem desenvolvida, formando uma quilha única (Fig. 44), semelhante à de $D$. glycera e ligeiramente maior que a encontrada em $D$. juno juno (Penz 1999; Tavares et al. 2002). Tubérculos médio-dorsais pouco projetados, presentes do quarto ao sexto segmentos abdominais (Figs. 34 e 46). Tubérculos supraespiraculares pequenos e localizados apenas no terceiro e quarto segmentos abdominais (Fig. 47). Tubérculos ventrais aos pares no quinto e sexto segmentos abdominais (Fig. 34).

Abertura do espiráculo mesotorácico em forma de fenda, sem tubérculo e com microtríquias simples, associadas à abertura (Figs. 48-49). Aspectos morfológicos deste espiráculo, como a presença ou ausência de tubérculo e a ultraestrutura das microtríquias pode ser uma boa fonte de caracteres taxonômicos em Lepidoptera (García-Barros \& Cano 1994), sendo que dentre os Heliconiini parece haver pouca variação (Paim et al. 2004, Silva et al. 2006). Demais espiráculos abdominais apresentam formato elíptico e aparato filtrador com microtríquias ramificadas (Fig. 50), sendo o do primeiro segmento abdominal encoberto pelas asas e o oitavo vestigial. O cremáster é truncado posteriormente com formato subquadrangular (Fig. 51). Na porção posterior do crêmaster estão presentes ganchos recurvados e subdivididos em duas pontas (Fig. 52).

Agradecimentos. Ao Departamento de Florestas e Áreas Protegidas do Estado do Rio Grande do Sul (DEFAP), pela autorização de coletas no Parque Estadual do Turvo (Projeto $\mathrm{n}^{\circ}$ 125). Ao Prof. João A. Jarenkow e Instituto de Biociências (UFRGS) pelo transporte para as coletas. Ao Centro de Microscopia Eletrônica da UFRGS, especialmente à Moema Q . Vieira, Luciano V. Taveira e Francis F. Darsie, pelo auxílio na preparação das amostras e operação do microscópio eletrônico de varredura. À Ana Carolina B. Aymone e Denis S. da Silva pelas críticas e sugestões, bem como a dois consultores anônimos pelas valiosas críticas. Ao CNPq, pela Bolsa de Iniciação Científica concedida ao primeiro autor (Proc. $\mathrm{n}^{\circ}$ 106325/2001-9). Este trabalho foi parcialmente financiado pelo CNPq (Proc. $n^{\circ}$ 478787/2001-4). Contribuição $n^{\circ} 541$ do Departamento de Zoologia, Universidade Federal do Rio Grande do Sul (UFRGS).

\section{REFERÊNCIAS}

Antunes, F. A.; A. O. Jr. Menezes; M. Tavares \& G. R. P. Moreira. 2002. Morfologia externa dos estágios imaturos de heliconíneos neotropicais: I. Eueides isabella dianasa (Hübner, 1816). Revista Brasileira de Entomologia 46: 601-610.

Araújo, A. M. \& V. L. S. Valente. 1981. Observações sobre alguns lepidópteros e drosofilídeos do Parque Estadual do Turvo. Ciência e Cultura 33: 1485-1490.

Beebe, W.; J. Crane \& H. Fleming. 1960. A comparison of eggs, larvae and pupae in fourteen species of heliconiine butterflies from Trinidad, W. I. Zoologica 45: 111-154.

Benson, W. W.; K. S., Jr. Brown \& L. E. Gilbert. 1975. Coevolution of plants and herbivores: passion vine butterflies. Evolution 32: 659680 .

Biezanko, C. M. 1949. Acraeidae, Heliconiidae et Nymphalidae de Pelotas e seus arredores (contribuição ao conhecimento da fisiografia do Rio Grande do Sul). Pelotas, Livraria do Globo, 16p. 
Biezanko, C. M.; A. Ruffinelli \& D. Link. 1978. Catálogo de lepidópteros do Uruguai. Revista do Centro de Ciências Rurais 8: $1-84$.

Brown, F. M. 1944. The egg, larva and chrysalis of Dione moneta Huebner. Bulletin of the Brooklyn Entomological Society 39: $132-134$.

Brown, K. S., Jr. 1981. The biology of Heliconius and related genera. Annual Review of Entomology 26: 427-456.

Brown, K. S. Jr. 1992. Borboletas da Serra do Japi: diversidade, hábitats, recursos alimentares e variação temporal, p. 142-187. In: L. P. C. Morellato (ed.). História Natural da Serra do Japí: Ecologia e preservação de uma área florestal no sudeste do Brasil. Campinas, UNICAMP/FAPESP, 322 p.

Brown, K. S. Jr. \& O. H. H. Mielke. 1972. The heliconians of Brazil (Lepidoptera: Nymphalidae). Part II. Introduction and general comments, with a supplementary revision of the tribe. Zoologica 57: $1-40$.

D'Abrera, B. 1984. Butterflies of the Neotropical region. Part II. Danaidae, Ithomiidae, Heliconidae \& Morphidae. Victoria, Hill House, vii + 173-384 p.

Dell'Erba, R.; L. A. Kaminski \& G. R. P. Moreira. 2005. O estágio de ovo dos Heliconiini (Lepidoptera: Nymphalidae) do Rio Grande do Sul, Brasil. Iheringia, Série Zoologia 95: 29-46.

DeVries, P. J. 1987. The butterflies of Costa Rica and their natural history. Papilionidae, Pieridae, Nymphalidae. Princeton, Princeton University, $327 \mathrm{p}$.

Duarte, M.; R. K. Robbins \& O. H. H. Mielke. 2005. Immature stages of Calycopis caulonia (Hewitson, 1877) (Lepidoptera, Lycaenidae, Theclinae, Eumaeini), with notes on rearing detritivorous hairstreaks on artificial diet. Zootaxa 1063: 1-31.

Emsley, M. G. 1963. A morphological study of imagine Heliconiinae (Lep.: Nymphalidae) with a consideration of the group. Zoologica 48: $85-130$.

Fleming, H. 1960. The first instar larvae of the Heliconiinae (Butterflies) of Trinidad, W. I. Zoologica 45: 91-110.

Freitas, A.V. L. 2003. Description of a new genus for "Euptychia" peculiaris (Nymphalidae: Satyrinae): immature stages and systematic position. Journal of the Lepidopterists' Society 57: 100-106.

García-Barros, E. \& J. M. Cano. 1994. Morfología de los tubérculos mesotorácicos de las pupas de algunos lepidópteros (Lepidoptera: Nymphalidae, Hesperiidae, Sphingidae). SHILAP Revista de Lepidopterologia 22: 249-258.

Garcias, G. L. 1983. Aspectos da biologia de cinco espécies de heliconíneos do anel mimético "laranja" (Lepidoptera: Nymphalidae). Dissertação de Mestrado. Porto Alegre, UFRGS, $88 \mathrm{p}$.

Gilbert, L. E. 1969. On the ecology of natural dispersal: Dione moneta poeyii in Texas (Nymphalidae). Journal of the Lepidopterists' Society 23: 177-185.

Gilbert, L. E. 1971. Butterfly-plant coevolution: has Passiflora adenopoda won selectional race with heliconiine butterflies? Science 172: 585-586.

Harvey, D. J. 1991. Higher classification of the Nymphalidae. Appendix B, p. 255-273. In: H. F. Nijhout (ed.). The development and evolution of butterfly wing patterns. Washington, Smithsonian Institution, $\mathrm{xvi}+297 \mathrm{p}$.

Hinton, H. E. 1946. On the homology and nomenclature of the setae of lepidopteran larvae, with some notes on the phylogeny of the Lepidoptera. Transactions of the Royal Entomological Society of London 97: 1-37.

Kaminski, L. A.; M. Tavares; V. G. Ferro \& G. R. P. Moreira. 2002. Morfologia externa dos estágios imaturos de heliconíneos neotropicais: III. Heliconius erato phyllis (Fabricius) (Lepidoptera:
Nymphalidae: Heliconiinae). Revista Brasileira de Zoologia 19: 977-993.

Kitching, I. J. 1984. The use of larval chaetotaxy in butterfly systematics, with special reference to the Danaini (Lepidoptera: Nymphalidae). Systematic Entomology 9: 49-61.

Lamas, G. 2004. Checklist: Part 4A. Hesperioidea - Papilionoidea. In: J. B. Heppner (ed.). Atlas of Neotropical Lepidoptera. Volume 5A. Gainesville, Association for Tropical Lepidoptera, Scientific Publishers, xxxiv $+428 \mathrm{p}$.

McCaffrey, J. 1984. Dione moneta poeyii Butler [1873] in New Mexico (Lepidoptera: Nymphalidae). Journal of Research on the Lepidoptera 23: 106-107.

Miller, J. S. 1991. Cladistics and classification of the Notodontidae (Lepidoptera: Noctuoidea) based on larval and adult morphology. Bulletin of the American Museum of Natural History 204: $1-230$.

Mosher, E. 1916. A classification of the Lepidoptera based on characters of the pupa. Bulletin of the Illinois State Laboratory of Natural History 12: 1-165.

Motta, P. C. 2003. Phylogenetic relationships of Ithomiinae based on first-instar larvae, p. 409-429. In: C. L. Boggs; W. B. Watt \& P. R. Ehrlich (eds.). Butterflies: ecology and evolution taking flight. Chicago, University of Chicago, 739 p.

Müller, W. 1886. Südamerikanische Nymphalidenraupen. Versuch eines naturlichen Systems der Nymphaliden. Zoologischen Jahrbüchern 1: 417-678.

Murray, D. 2001. Immatures stages and biology of Taygetis Hübner (Lepidoptera: Nymphalidae). Proceedings of the Entomological Society of Washington 103: 932-945.

Nakanishi, A. 1988. Study on the first instar larvae of the subfamily Nymphalinae (Lepidoptera, Nymphalidae). Special Bulletin of the Lepidopterological Society of Japan 6: 83-99.

Paim, A. C.; L. A. Kaminski \& G. R. P. Moreira. 2004. Morfologia externa dos estágios imaturos de heliconíneos neotropicais. IV. Dryas iulia alcionea (Lepidoptera: Nymphalidae: Heliconiinae). Iheringia, Série Zoologia 94: 25-35.

Paluch, M.; M. M. Casagrande \& O. H. H. Mielke. 2001. Estágios imaturos de Actinote carycina Jordan (Lepidoptera, Nymphalidae, Acraeinae). Revista Brasileira de Zoologia 18: 883-896.

Penz, C. M. 1999. Higher level phylogeny for the passion-vine butterflies (Lepidoptera: Heliconiinae) based on early stage and adult morphology. Zoological Journal of the Linnean Society 127: 277-344.

Peterson, A. 1962. Larvae of insects. An introduction to Neartic species. Part I Lepidoptera and plant infesting Hymenoptera. Ann Arbor, Edwards Brothers Inc., 315 p.

Silva, D. S. da; R. Dell'Erba; L. A. Kaminski \& G. R. P. Moreira. 2006. Morfologia externa dos estágios imaturos de heliconíneos neotropicais: V. Agraulis vanillae maculosa (Lepidoptera, Nymphalidae, Heliconiinae). Iheringia, Série Zoologia 96: 219228.

Snedecor, G. W. \& W. G. Cochran. 1980. Statistical methods. Ames, Iowa State University, $507 \mathrm{p}$.

Stehr, F. W. 1987. Order Lepidoptera, p. 288-305. In: F. W. Stehr, (ed.). Immature insects. Vol. I. Dubuque, Kendall/ Hunt Publishing Company, 975 p.

Tavares, M., L. A. Kaminski \& G. R. P. Moreira. 2002. Morfologia externa dos estágios imaturos de heliconíneos neotropicais: II. Dione juno juno (Cramer) (Lepidoptera: Nymphalidae: Heliconiinae). Revista Brasileira de Zoologia 19: 961-976.

Toledo, Z. D. A. 1991. Fauna del noroeste argentino. Contribucion al conocimiento de los lepidopteros argentinos. X. Agraulis vanilla maculosa (Stichel) (Lepidoptera, Rhopalocera, Heliconiidae). Acta Zoologica Lilloana 40: 21-31. 